\title{
Marital status and risk of physical frailty: A systematic review and meta-analysis
}

Gotaro Kojima, $\mathrm{MD}^{1,2,3}$, Kate Walters, $\mathrm{PhD}^{2}$, Steve Iliffe, FRCGP ${ }^{2}$, Yu Taniguchi, $\mathrm{PhD}^{4}$ Nanako Tamiya, $\mathrm{MD}, \mathrm{PhD}^{3}$,

${ }^{1}$ Videbimus Toranomon clinic, Tokyo, Japan

${ }^{2}$ Department of Primary Care and Population Health, University College London, London, UK

${ }^{3}$ Health Services Research \& Development Center, University of Tsukuba, Tsukuba, Japan

${ }^{4}$ Center for Health and Environmental Risk Research, National Institute for Environmental

Studies, Tsukuba, Japan

Corresponding Author:

Gotaro Kojima, MD

Videbimus Toranomon Clinic

Shimbashi Plaza Building 2F

4-9-1 Shimbashi, Minato, Tokyo 105-0004

Phone: +81-(0)3-6447-5028

Fax: +81-(0)3-6447-5267

Email: gotarokojima@yahoo.co.jp 


\begin{abstract}
Objectives: Evidence on associations between marital status and frailty is limited. The objective of this study was to perform a systematic review for associations between marital status and physical frailty and to perform a meta-analysis to combine findings.
\end{abstract}

Design: Systematic review and meta-analysis.

Setting and participants: Community-dwelling older people with mean age $\geq 60$.

Methods: Systematic literature search using five databases in February 2019 to identify longitudinal and cross-sectional studies examining associations between marital status and Fried's phenotype-based frailty status. Additional studies were searched for by reviewing the reference lists of relevant articles and conducting forward citation tracking of included articles. Odds ratio (OR) of marital status and frailty was pooled using a random-effects meta-analysis. Subgroup analysis and analyses stratified by gender and marital status (married, widowed, divorced/separated, never married) were completed.

\title{
Results:
}

A total of 1565 studies were found, from which 3 studies with longitudinal data and 35 studies with cross-sectional data were included. Although longitudinal studies suggested that married men had lower frailty risks than unmarried men while married women had higher frailty risks than widowed women, meta-analysis was not possible due to different methodologies. Meta-analyses of cross-sectional data from 35 studies including 80,754 individuals showed that unmarried individuals were almost twice more likely to be frail than married individuals (pooled $\mathrm{OR}=1.88,95 \% \mathrm{CI}=1.70-2.07$ ). A high degree of heterogeneity was observed $\left(\mathrm{I}^{2}=69 \%\right)$ and was partially explained by reasons for not being married and study location. The higher frailty risks in unmarried compared with married individuals were not statistically different ( $\mathrm{p}$ for difference $=0.62$ ).

Conclusions and Implications: The three and 35 studies were found providing longitudinal and cross-sectional data respectively regarding associations between marital status and frailty among community-dwelling older people. A meta-analysis of cross-sectional data showed almost twice higher frailty risk in unmarried individuals compared with married individuals. Marital status should be recognized as an important factor, and more longitudinal studies controlling for potential confounding factors are needed. 


\section{INTRODUCTION}

Age-related vulnerability, resulting from a gradual decline in physiological reserve in multiple systems and weakened resilience for maintaining homeostasis against stressors, can be conceptualized as frailty. ${ }^{1}$ Although a number of operational definitions of frailty have been proposed, to date no international consensus about how best to define frailty has been reached. ${ }^{1}$ Among existing definitions, the most commonly used one is the 'frailty phenotype' advocated by Fried and colleagues and derived from using the Cardiovascular Health Study. ${ }^{2}$ They defined frailty as a biological syndrome and considered individuals as frail when they meet three or more of five specific physical components: unintentional weight loss, selfreported exhaustion, weakness (grip strength), slow walking speed, and low physical activity. $^{2}$

Frailty is associated with negative health outcomes, such as falls, healthcare resource use, disability, and death, ${ }^{3-12}$ and can have a devastating impact on older people. Evidence shows that frailty is also associated with increased healthcare costs. ${ }^{13,14}$ Given that the number of older people worldwide is expected to increase due to ongoing population aging, frailty is considered a public health priority. ${ }^{15,16}$ Over the last two decades, the number of studies on frailty has exponentially increased and contributed to the field. Although frailty is more common among people of more advanced age,${ }^{17}$ frailty is neither an inevitable part of aging nor an irreversible decline in health toward death. Multiple studies have demonstrated that frailty is a dynamic state which can be reversed. ${ }^{18,19}$ Therefore, examining risk factors of frailty will further enhance our understanding of the pathophysiology of frailty.

Social factors, such as living alone or social isolation, appear to have significant associations with risk of frailty. ${ }^{20,21} \mathrm{We}$ also know that marital status has an impact on a number of health outcomes, including cardiovascular diseases or mortality. ${ }^{22,23}$ There seem to be gender effects on relationship between marital status and health, with men having greater health benefits than women. ${ }^{24}$ However, evidence on associations between marital status and frailty is scarce and limited. ${ }^{5}$ Therefore, the objectives of this review is thus to conduct a systematic review of the literature for the currently available evidence on marital status and frailty and to perform a meta-analysis to combine the findings and synthesize the first pooled evidence.

\section{METHODS}

\section{PICO for the systematic review}

Population: community-dwelling older people

Intervention/Exposure: being unmarried (widowed, divorced/separated, or never married in stratified analysis)

Comparison: being married

Outcome: frailty risks

\section{Search Strategy}

A systematic review of the literature was carried out by one investigator (**) in February 2019 in five electronic databases (Embase, Medline, PsycINFO, AMED, and CINAHL) within a time frame from January 2000 to February 2019. A protocol was developed a priori in accordance with the Preferred Reporting Items for Systematic Review and Meta-Analysis (PRISMA) statements ${ }^{25}$ and was registered at PROSPERO (http://www.crd.york.ac.uk/PROSPERO/display_record.php?ID=CRD42019124882). The Medical Subject Heading (MeSH) and free text terms used were as follows: [Marital status (MeSH) OR Marriage (MeSH) OR Widow(s) (MeSH) OR Widowhood (MeSH) OR Widows 
and widowers (MeSH) OR Divorce (MeSH) OR Single (marital status) (MeSH) OR Single person(s) (MeSH) OR Single women (MeSH) OR Single men (MeSH) OR "marri*" OR "unmarried" OR "widow*" OR "divorc*" OR "separate*"] AND [Frail elderly (MeSH) OR Frailty (MeSH) OR Frailty syndrome (MeSH) OR "frailty"]. The search was conducted using an explosion function when available and without language restriction. Titles, abstracts, and full-texts were screened and evaluated for eligibility by one investigator (GK). In order to identify additional studies, reference lists of included studies and relevant reviews were scrutinized and forward citation tracking of included and relevant studies was conducted.

\section{Study Selection}

Studies were included if they provided observational data of cross-sectional or prospective associations between marital status and frailty status among community-dwelling older people with a mean age of 60 years or older. Frailty had to be defined as a two-group categorical variable (frailty vs. non-frailty or frailty vs. prefrailty/robustness) by the frailty phenotype criteria or its modified versions. ${ }^{2}$ Randomized controlled trials, editorials, reviews, conference abstracts, book chapters, and dissertations were excluded. Studies that used specific populations, such as a sample of disease-specific patients, were excluded. On the occasion that two or more studies used the same cohort, the study with the largest sample size was included. Corresponding authors were contacted for additional information if necessary.

\section{Data Extraction}

Data were collected regarding study design (prospective or cross-sectional), first author, cohort name, publication year, location, sample size, proportion of female participants, mean age, age range, frailty definition, proportion of married participants, marital status category (married, divorced, separated, widowed, unmarried, never married), and effect size of frailty risk.

\section{Methodological Quality Assessment}

Prospective studies were assessed using the Newcastle-Ottawa scale for cohort studies (nine items) ${ }^{26}$ and cross-sectional studies were assessed using the Joanna Briggs Institute Critical Appraisal Checklist for Analytical Cross-Sectional Studies (eight items). ${ }^{27}$ Studies were considered to have adequate methodological quality and low risk of bias when their scores were five or higher.

\section{Statistical Analysis}

When two or more studies provided the same effect sizes of frailty risk, such as odds ratio (OR) or risk ratio, according to marital status, a meta-analysis was attempted to synthesize pooled risk estimates. Heterogeneity across the studies was assessed using a chi-square test and degree of heterogeneity was evaluated using the $\mathrm{I}^{2}$ statistic. A random-effects metaanalysis was used given the expected high degree of heterogeneity due to differences in methodologies and cultural backgrounds regarding marriage across the included studies. Three sets of supplementary analyses were conducted in order to explore potential causes of heterogeneity. First, gender-stratified meta-analyses were conducted, where effect sizes were combined among men and women separately. Second, subgroup meta-analyses based on location, sample size, and mean age were conducted. Third, effect sizes for each marital status (never married, divorced/separated, or widowed) compared with being married, were combined. Publication bias was examined using Egger's and Begg's tests. All statistical analyses were performed using the Review Manager 5 (Version 5.2, The Cochrane Collaboration, Copenhagen, Denmark). Two-sided $p$ value of $<0.05$ was considered statistically significant. 


\section{RESULTS \\ Selection Processes}

The search of five databases yielded 1536 studies and an additional 29 studies were found from other sources. After duplicates, randomized controlled trials, conference abstracts, and dissertations were removed, 956 studies were screened. The title and abstract screening excluded 549 studies and the full-texts of 60 studies were reviewed. A further 22 studies were removed due to using non-CHS criteria $(n=11)$, using the same cohort $(n=8)$, not providing relevant data $(\mathrm{n}=2)$, and using a selected sample $(\mathrm{n}=1)$. Thirty-eight studies ( 3 studies with prospective data and 35 studies with cross-sectional data) were included in this review. The cross-sectional data from 35 studies were used for meta-analysis. The flow chart of the literature search is summarized in Figure 1.

\section{Study Characteristics}

Table 1 summarizes three studies with longitudinal data ${ }^{28-30}$ and 35 studies with crosssectional data ${ }^{31-65}$ on associations between marital status and frailty.

\section{Methodological quality assessment}

Three longitudinal studies were considered to have adequate methodological quality according to the Newcastle-Ottawa scale for cohort studies (range=6-8, mean=7). The 8-item Joanna Briggs Institute Critical Appraisal Checklist for Analytical Cross-Sectional Studies was used for cross-sectional studies. Most of included cross-sectional studies (34/35) did not specifically focus on marital status and frailty but just provided the crude numbers of participants by marital status and frailty categories, from which unadjusted ORs were calculated. Therefore three criteria (confounders, strategies for confounders, and statistical analysis) were not applicable to these studies, and the remaining five criteria were used for evaluation. The 34 studies scored 4-5 out of 5 (mean=4.4) and the other study scored 5 out of 8 , so all of the studies were considered to have adequate methodological quality.

\section{Studies with longitudinal data}

Three longitudinal studies examined baseline marital status and subsequent frailty risks. Two of them used data regarding older people aged $\geq 65$ from the Progetto Veneto Anziani cohort. $^{29,30}$ The first study investigated risk of incident frailty, defined by the frailty phenotype, over 4.4 years according to marital status at baseline, and showed different effects of marital status on incident frailty risks by gender. ${ }^{29}$ While men who were widowed were significantly more likely to develop frailty than married men $(\mathrm{OR}=1.43,95 \% \mathrm{CI}=1.06-1.95)$, women who were widowed were significantly less likely to develop frailty than married women $(\mathrm{OR}=0.77,95 \% \mathrm{CI}=0.66-0.91) .{ }^{29} \mathrm{Men}$ who had never married had a significantly higher incident frailty risk $(\mathrm{OR}=3.84,95 \% \mathrm{CI}=2.76-5.35)$, however there was no significant association between never having been married and incident frailty risk among women. ${ }^{29}$ The focus of the other study was frailty transition patterns according to a variety of sociodemographic and health-related factors, including marital status. ${ }^{30}$ In this study, no clear explanation was provided regarding how marital status was categorized and what the reference group was and, in addition, the effect sizes regarding marital status and frailty transitions were only shown in graphs without an actual value and 95\% $\mathrm{CI}^{30}$ A US study including only older men showed that married men were significantly more likely to improve frailty status compared with unmarried men (fully adjusted $\mathrm{OR}=1.5,95 \% \mathrm{CI}=1.02-2.2$ for 
changing from prefrail to robust; fully adjusted $\mathrm{OR}=3.6,95 \% \mathrm{CI}=1.1-11.7$ for changing from frail to prefrail or robust) while marital status did not have any significant effects on worsening frailty (age- and site-adjusted $\mathrm{OR}=0.7-0.9) .{ }^{28} \mathrm{~A}$ meta-analysis was not possible for longitudinal studies due to different methodologies across the three studies (incident frailty ${ }^{29}$ or frailty status transitions ${ }^{28}$ ).

\section{Studies with cross-sectional data}

Cross-sectional data on the association between marital status and frailty were obtained from 35 studies, ${ }^{31-65}$ incorporating a total of 80,754 community-dwelling older people. It is of note that none of the studies focused specifically on marital status but most of them examined a variety of factors, including marital status, or showed the number of participants stratified by marital status and frailty status in a table of baseline characteristics. Ten studies were from Europe, nine were from Asia, six were from Brazil, four were from USA/Canada, and six from other countries. The size of the cohort ranged from $151^{34}$ to $8,744 .{ }^{58}$ One study consisted only of male participants ${ }^{35}$ and the rest used mixed-gender cohorts with $43.7 \%$ $70.7 \%$ female participants. The mean age of the cohorts ranged from 65.6 years $^{34}$ to 84.4 years. ${ }^{40}$ The proportion of those who were married ranged from $30.0 \%{ }^{40}$ to $84.1 \% .{ }^{34}$ The types of marital status categories used were combinations of married, divorced, separated, widowed, single, never married, and unmarried.

\section{Meta-analysis of cross-sectional associations between marital status and frailty}

Unadjusted ORs of associations between marital status and frailty were calculated based on the numbers of participants stratified by marital and frailty status for all studies except for one which showed an unadjusted OR in the text. ${ }^{32}$ In the main analysis marital status was dichotomized into "not married" (including never married, divorced, separated, widowed, single, or unmarried) and "married". Significant heterogeneity was observed $\left(\mathrm{I}^{2}=69 \%\right.$, $\mathrm{p}<0.001)$. A random-effects meta-analysis was used showing that those who were not married had an almost doubled odds of frailty compared with those who were married (35 studies: pooled $\mathrm{OR}=1.88,95 \% \mathrm{CI}=1.70-2.07, \mathrm{p}<0.001)$. Figure 2 shows a forest plot. No evidence of publication bias was observed based on Egger's and Begg's tests $(\mathrm{P}=0.52$ and 0.95 , respectively).

\section{Gender-stratified meta-analysis}

One study used a male-only cohort ${ }^{35}$ and another study showed data for men and women separately. ${ }^{58}$ However, the remaining 33 studies presented data of mixed gender populations. Upon request, additional data were provided from 15 studies and used for gender-stratified meta-analysis. For both men ( 16 studies: pooled $\mathrm{OR}=1.86,95 \% \mathrm{CI}=1.55-2.24, \mathrm{p}<0.001$, $\mathrm{I}^{2}=49 \%$ ) and women ( 15 studies: pooled $\mathrm{OR}=1.74,95 \% \mathrm{CI}=1.42-2.13, \mathrm{p}<0.001, \mathrm{I}^{2}=81 \%$ ), the unmarried participants had significantly higher risks of being frail compared with the married participants. No significant difference was observed in results between men and women ( $\mathrm{p}$ for group difference $=0.62$ ). The significant heterogeneity persisted in both gender groups.

\section{Subgroup meta-analysis}

Factors considered in the subgroup meta-analysis were location (Europe, Asia, Brazil, USA/Canada, and others), sample size (<2000 vs. $\geq 2000$ ), and mean age ( $<75$ vs. $\geq 75$ ). While there was a high degree of heterogeneity across the 35 included studies $\left(\mathrm{I}^{2}=69 \%\right)$, heterogeneity among studies from Europe $\left(\mathrm{I}^{2}=0 \%\right)$, Asia $\left(\mathrm{I}^{2}=0 \%\right)$, and Brazil $\left(\mathrm{I}^{2}=0 \%\right)$ was lower and not statistically significant. Frailty risks for being unmarried in USA/Canada $(\mathrm{OR}=1.81)$, Brazil $(\mathrm{OR}=1.39)$, and others $(\mathrm{OR}=1.49)$ were significantly lower than that in 
Europe ( $\mathrm{OR}=2.33)$. In subgroups stratified by sample size and mean age, a high degree of heterogeneity remained $\left(\mathrm{I}^{2}=42-85 \%\right)$ and there was no significant difference between the two stratified groups ( $\mathrm{n}<2000$ vs. $\mathrm{n} \geq 2000$, mean age $<75$ vs. $\geq 75$ ).

\section{Marital status-stratified meta-analysis}

Instead of calculating frailty risk for "not married" compared with "married", frailty risks of "widowed", "divorced/separated", or "never married", respectively, compared with "married" were separately calculated and pooled.

\section{Widowed vs. Married}

Widows/widowers were significantly more likely to be frail compared with those who were married ( 12 studies: pooled $\mathrm{OR}=2.17,95 \% \mathrm{CI}=1.89-2.50, \mathrm{I}^{2}=35 \%$ ).

\section{Divorced/Separated vs. Married}

Those who were divorced or separated were significantly more likely to be frail compared with those who were married ( 10 studies: pooled $\mathrm{OR}=1.86,95 \% \mathrm{CI}=1.47-2.35, \mathrm{I}^{2}=29 \%$ ). The risk of frailty was not significantly different from that of widows/widowers.

\section{Never married vs. Married}

Those who never married were significantly more likely to be frail compared with those who were married ( 7 studies: pooled $\mathrm{OR}=1.37,95 \% \mathrm{CI}=1.06-1.79, \mathrm{I}^{2}=0 \%$ ), but the risk of frailty was significantly lower than that of widows/widowers ( $p$ for difference<0.01).

The high heterogeneity among the 35 included studies $\left(\mathrm{I}^{2}=69 \%\right)$ fell and became nonsignificant in all three meta-analyses stratified by reasons for marital status $\left(\mathrm{I}^{2}=0-35 \%\right)$.

Results of the gender-stratified meta-analysis, subgroup meta-analysis, and meta-analysis stratified by marital status are summarized in Table 2.

\section{DISCUSSION}

Our systematic review identified a total of three studies with prospective data and 35 studies with cross-sectional data on associations between marital status and frailty. Unadjusted ORs of cross-sectional associations between marital status and frailty were combined, which showed pooled evidence that older people who were not married were significantly more likely to be physically frail than their married counterparts. The robustness of the association was shown in subgroup and stratified analyses. As expected, a high degree of heterogeneity was observed and was partially explained by the reasons for not being married (widowed, divorced/separated, or never married) and study location. Only few longitudinal studies were found, one of which suggested that older men may benefit from marriage than older women. ${ }^{29}$

It is not known why those who are not married are more likely to be frail compared with those who are married. Given that widows/widowers (pooled $\mathrm{OR}=2.11$ ) and the divorced/separated (pooled $\mathrm{OR}=1.73$ ) have higher odds of frailty risks than those who never married (pooled $\mathrm{OR}=1.37$ ), the stress of widowhood, divorce, or separation may increase the risk of frailty. Those who lose their partners may experience psychological and emotional stress and may suffer from loss of social support and social networks. These changes may have pervasive and perpetuating effects on health, increasing social vulnerability, 
depression, loneliness, and social isolation. ${ }^{66-68}$ It may also decrease positive health behaviors, such as exercise ${ }^{69}$ All of these consequences will increase risk of frailty. It is also of note that those who never married carry a significantly higher risk of frailty compared with those who are married, although the odds of the risk are lower than that of those who are widowed, divorced, or separated. Some studies have shown that single older people have worse health profiles than those who are married. For example, smoking and alcohol use are more common in those who are single. ${ }^{69}$ These factors may also contribute to the higher risk of frailty. Reverse causality may be possible. Those who are frail may be associated with illhealth in themselves and their spouse, sharing the risk factors, ${ }^{70}$ and therefore are more likely to lose the spouses.

The degree of the association between marital status and frailty varied across locations. The highest risks were observed in Europe and Asia ( $\mathrm{OR}=2.33$ and 2.25, respectively) and risks were lowest in Brazil $(\mathrm{OR}=1.39)$. It can be speculated that definitions of marriage and social norm of marriage may differ geographically.

One of the main strengths of this review was its robust methodology, with reproducible search strategy and comprehensive search words, using multiple databases. A total of 35 ORs, although unadjusted, were combined using a meta-analysis. Three series of supplementary analyses were conducted to explore the potential cause of high heterogeneity and found that reasons for not being married and study location may partially explain the heterogeneity.

There are potential limitations. First, only cross-sectional data were able to be pooled, therefore causal relationships could not be inferred. Second, regardless of the large number of cross-sectional studies included, very few of them specifically focused on the association between marital status and frailty, while many used marital status as one of the covariates for adjustment. Therefore, only unadjusted ORs were available for meta-analysis. It should be noted that the longitudinal study showed, controlling for various confounders including age, disabilities, cognition, depression, physical and social factors, that married men had lower risks of frailty while widowed women had a lower risk of frailty compared with married women. ${ }^{29}$ Third, the current review only considered the frailty phenotype criteria, which focused mainly on physical factors, and the findings may not be generalizable to data based on other frailty criteria. Some of the frailty phenotype criteria are self-reported (physical activity, exhaustion, and weight loss), which could be influenced by cognitive and social factors that are related to the different categories of unmarried status. Although the frailty phenotype has been mostly widely used, ${ }^{71}$ this operational definition of frailty focuses only on the physical components of frailty and does not include other components, such as cognition. Some experts consider that frailty is as a multidimensional construct and should include physical, cognitive, psychological, and social factors. ${ }^{72}$ It should be noted that frailty phenotype is merely one of the many definitions of frailty and has not yet been recognized as the gold standard. In addition, it is unknown if the findings of this meta-analysis are a real association between marital status and frailty, or are just results related to specific components of the physical frailty phenotype or other non-physical factors. However, the frailty phenotype defines frailty operationally as a syndrome and may make frailty more tractable than other frailty models, such as the Frailty Index. Lastly, the screening processes of the systematic review were conducted by one investigator only and important studies may have been missed.

\section{Conclusion and implications}


This systematic review and meta-analysis showed pooled cross-sectional evidence that community-dwelling older people who are not married are significantly more likely to be frail than those who are married. The association between marital status and frailty was higher for those who were widowed or divorced than those who had never married and varied by location. For future research in this field, marital status should be recognized as an important factor, and more longitudinal studies examining marital status and frailty risk, especially each of frailty components, and controlling for potential confounding factors are needed.

\section{ACKNOWLEDGMENT}

We are grateful to the authors for sharing additional data. ${ }^{31,33,39,43,44,49,51,52,55,58,63,64,73-75}$

\section{CONFLICTS OF INTEREST}

None.

\section{REFERENCES}

1. Clegg, A, Young, J, Iliffe, S, et al. Frailty in elderly people. Lancet (London, England) 2013;381(9868):752-762.

2. Fried, LP, Tangen, CM, Walston, J, et al. Frailty in older adults: evidence for a phenotype. The journals of gerontology Series A, Biological sciences and medical sciences 2001;56(3):M146-156.

3. Vermeiren, S, Vella-Azzopardi, R, Beckwee, D, et al. Frailty and the Prediction of Negative Health Outcomes: A Meta-Analysis. Journal of the American Medical Directors Association 2016;17(12):1163.e1161-1163.e1117.

4. Kojima, G. Frailty Defined by FRAIL Scale as a Predictor of Mortality: A Systematic Review and Meta-analysis. Journal of the American Medical Directors Association 2018;19(6):480-483.

5. Feng, Z, Lugtenberg, M, Franse, C, et al. Risk factors and protective factors associated with incident or increase of frailty among community-dwelling older adults: A systematic review of longitudinal studies. PloS one 2017;12(6):e0178383.

6. Kojima, G. Frailty as a Predictor of Nursing Home Placement among CommunityDwelling Older Adults: A Systematic Review and Meta-analysis. Journal of Geriatric Physical Therapy 2018;41(1):42-48.

7. Kojima, G, Taniguchi, Y, Kitamura, A, et al. Are the Kihon Checklist and the KaigoYobo Checklist compatible with the Frailty Index? Journal of the American Medical Directors Association 2018;19(9):797-800.

8. Kojima, G. Quick and Simple FRAIL Scale Predicts Incident Activities of Daily Living (ADL) and Instrumental ADL (IADL) Disabilities: A Systematic Review and Meta-analysis. Journal of the American Medical Directors Association 2018;19(12):1063-1068.

9. Kojima, G, Iliffe, S, Walters, K. Frailty index as a predictor of mortality: a systematic review and meta-analysis. Age and ageing 2018;47(2):193-200.

10. Kojima, G. Frailty as a Predictor of Emergency Department Utilization among Community-Dwelling Older People: A Systematic Review and Meta-Analysis. Journal of the American Medical Directors Association 2019;20(1):103-105.

11. Kojima, G. Prevalence of Frailty in Nursing Homes: A Systematic Review and MetaAnalysis. Journal of the American Medical Directors Association 2015;16(11):940945. 
12. Kojima, G. Frailty as a Predictor of Future Falls Among Community-Dwelling Older People: A Systematic Review and Meta-Analysis. Journal of the American Medical Directors Association 2015;16(12):1027-1033.

13. Hajek, A, Bock, JO, Saum, KU, et al. Frailty and healthcare costs-longitudinal results of a prospective cohort study. Age and ageing 2018;47(2):233-241.

14. Kojima, G. Increased healthcare costs associated with frailty among communitydwelling older people: A systematic review and meta-analysis. Archives of gerontology and geriatrics 2019.

15. Cesari, M, Prince, M, Thiyagarajan, JA, et al. Frailty: An Emerging Public Health Priority. Journal of the American Medical Directors Association 2016;17(3):188-192.

16. Kojima, G, Liljas, AEM, Iliffe, S. Frailty syndrome: implications and challenges for health care policy. Risk Manag Healthc Policy 2019;12:23-30.

17. Collard, RM, Boter, H, Schoevers, RA, et al. Prevalence of frailty in communitydwelling older persons: a systematic review. Journal of the American Geriatrics Society 2012;60(8):1487-1492.

18. Kojima, G, Taniguchi, Y, Iliffe, S, et al. Transitions between frailty states among community-dwelling older people: A systematic review and meta-analysis. Ageing research reviews 2019;50:81-88.

19. Kojima, G, Taniguchi, Y, Iliffe, S, et al. Factors Associated With Improvement in Frailty Status Defined Using the Frailty Phenotype: A Systematic Review and Metaanalysis. Journal of the American Medical Directors Association 2019.

20. Gale, CR, Westbury, L, Cooper, C. Social isolation and loneliness as risk factors for the progression of frailty: the English Longitudinal Study of Ageing. Age and ageing 2018;47(3):392-397.

21. Yamanashi, H, Shimizu, Y, Nelson, M, et al. The association between living alone and frailty in a rural Japanese population: the Nagasaki Islands study. J Prim Health Care 2015;7(4):269-273.

22. Wong, CW, Kwok, CS, Narain, A, et al. Marital status and risk of cardiovascular diseases: a systematic review and meta-analysis. Heart 2018;104(23):1937-1948.

23. Robards, J, Evandrou, M, Falkingham, J, et al. Marital status, health and mortality. Maturitas 2012;73(4):295-299.

24. Tatangelo, G, McCabe, M, Campbell, S, et al. Gender, marital status and longevity. Maturitas 2017;100:64-69.

25. Moher, D, Liberati, A, Tetzlaff, J, et al. Preferred reporting items for systematic reviews and meta-analyses: the PRISMA statement. BMJ (Clinical research ed) 2009;339:b2535.

26. Wells, GA, Shea, D, O'Connell, D, et al. The Newcastle-Ottawa Scale (NOS) for assessing the quality of nonrandomised studies in meta-analyses; http://www.ohri.ca/programs/clinical_epidemiology/oxford.asp. Accessed 23 February 2019.

27. Office for National Statistics, Population Ageing in the United Kingdom, its Constituent Countries and the European Union; 2012. http://www.ons.gov.uk/ons/dcp171776_258607.pdf. Accessed 2 March 2016.

28. Pollack, LR, Litwack-Harrison, S, Cawthon, PM, et al. Patterns and Predictors of Frailty Transitions in Older Men: The Osteoporotic Fractures in Men Study. Journal of the American Geriatrics Society 2017;65(11):2473-2479.

29. Trevisan, C, Veronese, N, Maggi, S, et al. Marital Status and Frailty in Older People: Gender Differences in the Progetto Veneto Anziani Longitudinal Study. Journal of women's health (2002) 2016;25(6):630-637. 
30. Trevisan, C, Veronese, N, Maggi, S, et al. Factors Influencing Transitions Between Frailty States in Elderly Adults: The Progetto Veneto Anziani Longitudinal Study. Journal of the American Geriatrics Society 2017;65(1):179-184.

31. Ahmad, NS, Hairi, NN, Said, MA, et al. Prevalence, transitions and factors predicting transition between frailty states among rural community-dwelling older adults in Malaysia. PloS one 2018;13(11):e0206445.

32. Alcala, MV, Puime, AO, Santos, MT, et al. [Prevalence of frailty in an elderly Spanish urban population. Relationship with comorbidity and disability]. Atencion primaria 2010;42(10):520-527.

33. Aliberti, MJR, Cenzer, IS, Smith, AK, et al. Assessing Risk for Adverse Outcomes in Older Adults: The Need to Include Both Physical Frailty and Cognition. Journal of the American Geriatrics Society 2019;67(3):477-483.

34. Al-Kuwaiti, SJ, Aziz, F, Blair, I. Frailty in Community-Dwelling Older People in Abu Dhabi, United Arab Emirates: A Cross-Sectional Study. Frontiers in public health 2015;3:248.

35. Cawthon, PM, Marshall, LM, Michael, Y, et al. Frailty in older men: prevalence, progression, and relationship with mortality. Journal of the American Geriatrics Society 2007;55(8):1216-1223.

36. dos Santos Tavares, DM, de Freitas Corrêa, TA, Dias, FA, et al. Frailty syndrome and socioeconomic and health characteristics among older adults. 2017;48(3):126-131.

37. Ferriolli, E, Pessanha, F, Moreira, VG, et al. Body composition and frailty profiles in Brazilian older people: Frailty in Brazilian Older People Study-FIBRA-BR. Archives of gerontology and geriatrics 2017;71:99-104.

38. Filippin, LI, Miraglia, F, Leite, JCC, et al. Identifying frailty syndrome with TUG test in home-dwelling elderly. 2017;11(2):80-87.

39. Gijon-Conde, T, Graciani, A, Lopez-Garcia, E, et al. Frailty, Disability, and Ambulatory Blood Pressure in Older Adults. Journal of the American Medical Directors Association 2018;19(5):433-438.

40. Grden, CRB, Lenardt, MH, Sousa, JAV, et al. Associations between frailty syndrome and sociodemographic characteristics in long-lived individuals of a community. Revista latino-americana de enfermagem 2017;25:e2886.

41. Gross, CB, Kolankiewicz, ACB, Schmidt, CR, et al. Frailty levels of elderly people and their association with sociodemographic characteristics. 2018;31(2):209-216.

42. Herr, M, Arvieu, JJ, Ankri, J, et al. What is the duration of life expectancy in the state of frailty? Estimates in the SIPAF study. European journal of ageing 2018;15(2):165173.

43. Jurschik, P, Nunin, C, Botigue, T, et al. Prevalence of frailty and factors associated with frailty in the elderly population of Lleida, Spain: the FRALLE survey. Archives of gerontology and geriatrics 2012;55(3):625-631.

44. Lewis, EG, Coles, S, Howorth, K, et al. The prevalence and characteristics of frailty by frailty phenotype in rural Tanzania. BMC geriatrics 2018;18(1):283.

45. Lin, CC, Li, CI, Chang, CK, et al. Reduced health-related quality of life in elders with frailty: a cross-sectional study of community-dwelling elders in Taiwan. PloS one 2011;6(7):e21841.

46. Llibre Jde, J, Lopez, AM, Valhuerdi, A, et al. Frailty, dependency and mortality predictors in a cohort of Cuban older adults, 2003-2011. MEDICC review 2014;16(1):24-30.

47. Masel, MC, Howrey, B, Peek, MK. The effect of acculturation on frailty among older Mexican Americans. Journal of aging and health 2011;23(4):704-713. 
48. Moreno-Tamayo, K, Manrique-Espinoza, B, Rosas-Carrasco, O, et al. Sleep complaints are associated with frailty in Mexican older adults in a rural setting. Geriatrics \& gerontology international 2017;17(12):2573-2578.

49. Nascimento, CMC, Zazzetta, MS, Gomes, GAO, et al. Higher levels of tumor necrosis factor beta are associated with frailty in socially vulnerable communitydwelling older adults. BMC geriatrics 2018;18(1):268.

50. Ni Mhaolain, AM, Fan, CW, Romero-Ortuno, R, et al. Frailty, depression, and anxiety in later life. International psychogeriatrics 2012;24(8):1265-1274.

51. Ntanasi, E, Yannakoulia, M, Mourtzi, N, et al. Prevalence and Risk Factors of Frailty in a Community-Dwelling Population: The HELIAD Study. Journal of aging and health 2018:898264318801735.

52. Op het Veld, LP, van Rossum, E, Kempen, GI, et al. Fried phenotype of frailty: crosssectional comparison of three frailty stages on various health domains. BMC geriatrics 2015;15:77.

53. Peklar, J, O'Halloran, AM, Maidment, ID, et al. Sedative load and frailty among community-dwelling population aged $>/=65$ years. Journal of the American Medical Directors Association 2015;16(4):282-289.

54. Rahi, B, Ajana, S, Tabue-Teguo, M, et al. High adherence to a Mediterranean diet and lower risk of frailty among French older adults community-dwellers: Results from the Three-City-Bordeaux Study. Clinical nutrition (Edinburgh, Scotland) 2018;37(4):1293-1298.

55. Sanchez-Garcia, S, Garcia-Pena, C, Salva, A, et al. Frailty in community-dwelling older adults: association with adverse outcomes. Clinical interventions in aging 2017;12:1003-1011.

56. Sanchez-Garcia, S, Sanchez-Arenas, R, Garcia-Pena, C, et al. Frailty among community-dwelling elderly Mexican people: prevalence and association with sociodemographic characteristics, health state and the use of health services. Geriatrics \& gerontology international 2014;14(2):395-402.

57. Siriwardhana, DD, Weerasinghe, MC, Rait, G, et al. Prevalence of frailty in rural community-dwelling older adults in Kegalle district of Sri Lanka: a population-based cross-sectional study. BMJ open 2019;9(1):e026314.

58. Thompson, MQ, Theou, O, Karnon, J, et al. Frailty prevalence in Australia: Findings from four pooled Australian cohort studies. Australasian journal on ageing 2018;37(2):155-158.

59. Vaingankar, JA, Chong, SA, Abdin, E, et al. Prevalence of frailty and its association with sociodemographic and clinical characteristics, and resource utilization in a population of Singaporean older adults. 2017;17(10):1444-1454.

60. Veronese, N, Solmi, M, Maggi, S, et al. Frailty and incident depression in community-dwelling older people: results from the ELSA study. International journal of geriatric psychiatry 2017;32(12):e141-e149.

61. Wei, K, Nyunt, MSZ, Gao, Q, et al. Frailty and Malnutrition: Related and Distinct Syndrome Prevalence and Association among Community-Dwelling Older Adults: Singapore Longitudinal Ageing Studies. Journal of the American Medical Directors Association 2017;18(12):1019-1028.

62. Wong, CH, Weiss, D, Sourial, N, et al. Frailty and its association with disability and comorbidity in a community-dwelling sample of seniors in Montreal: a cross-sectional study. Aging clinical and experimental research 2010;22(1):54-62.

63. Wu, C, Smit, E, Xue, QL, et al. Prevalence and Correlates of Frailty Among Community-Dwelling Chinese Older Adults: The China Health and Retirement 
Longitudinal Study. The journals of gerontology Series A, Biological sciences and medical sciences 2017;73(1):102-108.

64. Yamanashi, H, Shimizu, Y, Koyamatsu, J, et al. Multiple somatic symptoms and frailty: cross-sectional study in Japanese community-dwelling elderly people. Family practice 2016;33(5):453-460.

65. Mohd Hamidin, FA, Adznam, SN, Ibrahim, Z, et al. Prevalence of frailty syndrome and its associated factors among community-dwelling elderly in East Coast of Peninsular Malaysia. SAGE open medicine 2018;6:2050312118775581.

66. Kohler, CA, Evangelou, E, Stubbs, B, et al. Mapping risk factors for depression across the lifespan: An umbrella review of evidence from meta-analyses and Mendelian randomization studies. Journal of psychiatric research 2018;103:189-207.

67. Beal, C. Loneliness in older women: a review of the literature. Issues in mental health nursing 2006;27(7):795-813.

68. Grenade, L, Boldy, D. Social isolation and loneliness among older people: issues and future challenges in community and residential settings. Australian health review : a publication of the Australian Hospital Association 2008;32(3):468-478.

69. Keenan, K, Ploubidis, GB, Silverwood, RJ, et al. Life-course partnership history and midlife health behaviours in a population-based birth cohort. Journal of epidemiology and community health 2017;71(3):232-238

70. Hippisley-Cox, J, Coupland, C, Pringle, M, et al. Married couples' risk of same disease: cross sectional study. BMJ (Clinical research ed) 2002;325(7365):636.

71. Buta, BJ, Walston, JD, Godino, JG, et al. Frailty assessment instruments: Systematic characterization of the uses and contexts of highly-cited instruments. Ageing research reviews 2016;26:53-61.

72. de Vries, NM, Staal, JB, van Ravensberg, CD, et al. Outcome instruments to measure frailty: a systematic review. Ageing research reviews 2011;10(1):104-114.

73. Dos Santos Tavares, DM, de Freitas Correa, TA, Dias, FA, et al. Frailty syndrome and socioeconomic and health characteristics among older adults. Colomb Med (Cali) 2017;48(3):126-131.

74. Filippin, LI, Miraglia, F, Leite, JCC, et al. Identifying frailty syndrome with tug test in home-dwelling elderly. Geriatrics, Gerontology and Aging 2017;11(2):80-87.

75. Vaingankar, JA, Chong, SA, Abdin, E, et al. Prevalence of frailty and its association with sociodemographic and clinical characteristics, and resource utilization in a population of Singaporean older adults. Geriatrics \& gerontology international 2017;17(10):1444-1454. 
Table 1. Summary of cross-sectional studies on frailty and marital status among community-dwelling older people.

\begin{tabular}{|c|c|c|c|c|c|c|c|}
\hline Author/Year/Study & Location & $\begin{array}{c}\text { Sample } \\
\text { size }\end{array}$ & $\begin{array}{l}\text { Female } \\
(\%)\end{array}$ & $\begin{array}{c}\text { Age } \\
\text { (range) }\end{array}$ & $\begin{array}{l}\text { Frailty } \\
\text { criteria }\end{array}$ & Married & Associations between marital status and frailty risk \\
\hline \multicolumn{8}{|l|}{ Longitudinal } \\
\hline $\begin{array}{l}\text { Pollack } 2017 \\
\text { MrOS study }\end{array}$ & USA & 4518 & $0 \%$ & $\begin{array}{l}73.4 \\
(\geq 65)\end{array}$ & $\mathrm{mCHS}$ & $82.9 \%$ & $\begin{array}{l}\text { Frailty transition patterns for being married compared with being unmarried: } \\
\text { Age- and site-aOR=1.6 }(95 \% \mathrm{CI}=1.1-2.2) \text { for changing from prefrail to robust. } \\
\text { Fully aOR=1.5 }(95 \% \mathrm{CI}=1.02-2.2) \text { for changing from prefrail to robust. } \\
\text { Age- and site-aOR=4.3 }(95 \% \mathrm{CI}=1.8-10.5) \text { for changing from frail to prefrail or robust } \\
\text { Fully aOR=2.6 }(95 \% \mathrm{CI}=1.1-11.7) \text { for changing from frail to prefrail or robust. } \\
\text { Age- and site-aOR=0.9 }(95 \% \mathrm{CI}=0.7-1.2) \text { for changing from robust to prefrail, frail, or death } \\
\text { Age- and site-aOR=0.9 }(95 \% \mathrm{CI}=0.7-1.1) \text { for changing from prefrail to frail or death } \\
\text { Age- and site-aOR=0.7 }(95 \% \mathrm{CI}=0.5-1.0) \text { for changing from frail to death }\end{array}$ \\
\hline $\begin{array}{l}\text { Trevisan } 2017 \\
\text { Pro.V.A. }\end{array}$ & Italy & 2925 & $63.3 \%$ & $\begin{array}{l}74.4 \\
(\geq 65)\end{array}$ & $\mathrm{mCHS}$ & - & $\begin{array}{l}\text { Unable to described because age- and gender-adjusted ORs for frailty transitions were only } \\
\text { shown in graphs, and marital status categorization and reference group were not explained in } \\
\text { the text. }\end{array}$ \\
\hline $\begin{array}{l}\text { Trevisan } 2016 \\
\text { Pro.V.A. }\end{array}$ & Italy & 1887 & $61.2 \%$ & $\begin{array}{l}74.2 \\
(\geq 65)\end{array}$ & $\mathrm{mCHS}$ & $77.5 \%$ & $\begin{array}{l}\text { Incident frailty, being married as reference } \\
\text { Women: } \\
\text { aOR=1.19 (0.96-1.49) for never married } \\
\text { aOR=0.77 (0.66-0.91) for widows } \\
\text { Men: } \\
\text { aOR=3.84 (2.76-5.35) for never married } \\
\text { aOR=1.43 (1.06-1.95) for widowers }\end{array}$ \\
\hline \multicolumn{8}{|l|}{ Cross-sectional } \\
\hline Siriwardhana 2019 & Sri Lanka & 746 & $56.7 \%$ & $\begin{array}{c}68 \\
(\geq 60)\end{array}$ & $\mathrm{mCHS}$ & $61.3 \%$ & $\begin{array}{l}\text { Divorced, widowed, separated, and never married: } \\
\text { cOR }=2.00(95 \% \mathrm{CI}=1.33-2.99)\end{array}$ \\
\hline Ahmad 2018 & Malaysia & 2310 & $59.6 \%$ & $(\geq 65)$ & $\mathrm{mCHS}$ & $62.9 \%$ & $\begin{array}{l}\text { Divorce, widowed, and single: } \\
\text { cOR=2.37 (95\%CI=1.79-3.14) }\end{array}$ \\
\hline $\begin{array}{l}\text { Aliberti } 2018 \\
\text { HRS }\end{array}$ & USA & 7338 & $54.9 \%$ & $\begin{array}{l}74.4 \\
(\geq 50)\end{array}$ & $\mathrm{mCHS}$ & $62.4 \%$ & $\begin{array}{l}\text { Divorce, widowed, and single: } \\
\text { cOR }=2.22(95 \% \mathrm{CI}=1.95-2.53)\end{array}$ \\
\hline $\begin{array}{l}\text { Gijon-Conde } 2018 \\
\text { Seniors-ENRICA }\end{array}$ & Spain & 1047 & $49.2 \%$ & $\begin{array}{c}71.1 \\
(>60)\end{array}$ & $\mathrm{mCHS}$ & $71.3 \%$ & $\begin{array}{l}\text { Separated, widowed, and single: } \\
\text { cOR }=1.95(95 \% \mathrm{CI}=1.16-3.28)\end{array}$ \\
\hline Gross 2018 & Brazil & 555 & $60.9 \%$ & $\begin{array}{l}71.1 \\
(\geq 60)\end{array}$ & $\mathrm{mCHS}$ & $64.0 \%$ & $\begin{array}{l}\text { Divorce, widowed, and single: } \\
\text { cOR }=1.35(95 \% \mathrm{CI}=0.94-1.95)\end{array}$ \\
\hline Lewis 2018 & Tanzania & 196 & $57.9 \%$ & $\begin{array}{l}74.8 \\
(\geq 60)\end{array}$ & $\mathrm{mCHS}$ & $49.5 \%$ & $\begin{array}{l}\text { Divorce, widowed, separated, and single: } \\
\text { cOR=2.78 ( } 95 \% \mathrm{CI}=1.25-6.19)\end{array}$ \\
\hline Mohd Hamidin 2018 & Malaysia & 279 & $57.7 \%$ & $\begin{array}{c}73.3 \\
(63-99)\end{array}$ & $\mathrm{mCHS}$ & $48.7 \%$ & $\begin{array}{l}\text { Divorced, widowed, and single: } \\
\text { cOR=3.88 (95\%CI }=1.93-7.78)\end{array}$ \\
\hline
\end{tabular}




\begin{tabular}{|c|c|c|c|c|c|c|c|}
\hline Author/Year/Study & Location & $\begin{array}{c}\text { Sample } \\
\text { size }\end{array}$ & $\begin{array}{c}\text { Female } \\
(\%)\end{array}$ & $\begin{array}{c}\text { Age } \\
\text { (range) }\end{array}$ & $\begin{array}{l}\text { Frailty } \\
\text { criteria }\end{array}$ & Married & Associations between marital status and frailty risk \\
\hline Nascimento 2018 & Brazil & 347 & $56.2 \%$ & $\begin{array}{c}70.1 \\
(>60)\end{array}$ & mCHS & $57.9 \%$ & $\begin{array}{l}\text { Without marital partner: } \\
\text { cOR=1.38 (95\%CI=0.88-2.18) }\end{array}$ \\
\hline $\begin{array}{l}\text { Ntanasi } 2018 \\
\text { HELIAD }\end{array}$ & Greece & 1867 & $58.6 \%$ & $\begin{array}{l}73.5 \\
(\geq 65)\end{array}$ & $\mathrm{mCHS}$ & $74.4 \%$ & $\begin{array}{l}\text { Not married: } \\
\text { cOR=2.19 }(95 \% \mathrm{CI}=1.37-3.50)\end{array}$ \\
\hline $\begin{array}{l}\text { Rahi } 2018 \\
\text { Three-City Study }\end{array}$ & France & 560 & $63.2 \%$ & $\begin{array}{l}81.7 \\
(\geq 75)\end{array}$ & $\mathrm{mCHS}$ & $49.6 \%$ & $\begin{array}{l}\text { Divorce, widowed, separated, and single: } \\
\text { cOR=1.54 }(95 \% \mathrm{CI}=0.95-2.49)\end{array}$ \\
\hline $\begin{array}{l}\text { Thompson } 2018 \\
\text { DYNOPTA \& NWAHS }\end{array}$ & Australia & 8744 & $86 \%$ & $\begin{array}{c}80 \\
(>65)\end{array}$ & $\mathrm{mCHS}$ & $46.2 \%$ & $\begin{array}{l}\text { Divorce, widowed, and never married: } \\
\text { cOR=1.41 (95\% } \mathrm{CI}=1.27-1.56)\end{array}$ \\
\hline $\begin{array}{l}\text { Ferriolli } 2017 \\
\text { FIBRA }\end{array}$ & Brazil & 5626 & $66.2 \%$ & $\begin{array}{r}73.1 \\
(\geq 65)\end{array}$ & $\mathrm{mCHS}$ & $49.9 \%$ & $\begin{array}{l}\text { Divorced, widowed, and single: } \\
\text { cOR }=1.53 \text { (95\% } \mathrm{CI}=1.26-1.86)\end{array}$ \\
\hline Flippin 2017 & Brazil & 322 & $60.6 \%$ & $\begin{array}{l}67.8 \\
(\geq 60)\end{array}$ & $\mathrm{mCHS}$ & $57.8 \%$ & $\begin{array}{l}\text { Divorced, widowed, and single: } \\
\text { cOR=1.31 (95\%CI=0.76-2.28) }\end{array}$ \\
\hline Grden 2017 & Brazil & 243 & $66.3 \%$ & $\begin{array}{r}84.4 \\
(>80)\end{array}$ & $\mathrm{mCHS}$ & $30.0 \%$ & $\begin{array}{l}\text { Widowed and single: } \\
\text { cOR=1.94 (95\% CI }=0.81-4.66)\end{array}$ \\
\hline $\begin{array}{l}\text { Herr } 2017 \\
\text { SIPAF }\end{array}$ & France & 1926 & $59.4 \%$ & $\begin{array}{r}83.3 \\
(\geq 70)\end{array}$ & $\mathrm{mCHS}$ & $45.0 \%$ & $\begin{array}{l}\text { Not married: } \\
\text { cOR=2.57 (95\% CI=2.01-3.28) }\end{array}$ \\
\hline $\begin{array}{l}\text { Moreno-Tamayo } 2017 \\
\text { Rural Frailty Study }\end{array}$ & Mexico & 591 & $52 . \%$ & $\begin{array}{r}76.3 \\
(\geq 70)\end{array}$ & $\mathrm{mCHS}$ & $48.6 \%$ & $\begin{array}{l}\text { Not married: } \\
\text { cOR=1.39 }(95 \% \mathrm{CI}=0.82-2.36)\end{array}$ \\
\hline $\begin{array}{l}\text { Sánchez-García } 2017 \\
\text { COSFOMA }\end{array}$ & Mexico & 1252 & $59.9 \%$ & $(\geq 60)$ & $\mathrm{mCHS}$ & $59.4 \%$ & $\begin{array}{l}\text { Widowed and single: } \\
\text { cOR=1.86 (95\%CI=1.41-2.46) }\end{array}$ \\
\hline Tavares 2017 & Brazil & 1608 & $64.4 \%$ & $(\geq 60)$ & $\mathrm{mCHS}$ & $42.7 \%$ & $\begin{array}{l}\text { Without marital companion: } \\
\mathrm{cOR}=1.13(95 \% \mathrm{CI}=0.84-1.51)\end{array}$ \\
\hline $\begin{array}{l}\text { Vaingankar } 2017 \\
\text { Well-being of the Singapore } \\
\text { Elderly Study }\end{array}$ & Singapore & 2101 & $53.9 \%$ & $\begin{array}{c}69 \\
(\geq 60)\end{array}$ & $\mathrm{mCHS}$ & $63.2 \%$ & $\begin{array}{l}\text { Divorce, widowed, separated, and single: } \\
\text { cOR=1.86 }(95 \% \text { CI }=1.36-2.53)\end{array}$ \\
\hline $\begin{array}{l}\text { Veronese } 2017 \\
\text { ELSA }\end{array}$ & UK & 4077 & $53.0 \%$ & $\begin{array}{l}70.9 \\
(\geq 60)\end{array}$ & $\mathrm{mCHS}$ & $64.8 \%$ & $\begin{array}{l}\text { Divorced, single, and not married: } \\
\text { cOR=2.02 }(95 \% \mathrm{CI}=1.57-2.60)\end{array}$ \\
\hline $\begin{array}{l}\text { Wei } 2017 \\
\text { SLAS-1 \& } 2\end{array}$ & Singapore & 5685 & $62.8 \%$ & $\begin{array}{r}66.6 \\
(>55) \\
\end{array}$ & $\mathrm{mCHS}$ & $69.4 \%$ & $\begin{array}{l}\text { Divorced, widowed, and single: } \\
\text { cOR=2.57 (95\%CI }=2.00-3.31)\end{array}$ \\
\hline $\begin{array}{l}\text { Wu } 2017 \\
\text { CHARLS }\end{array}$ & China & 5301 & $49.4 \%$ & $(\geq 60)$ & $\mathrm{mCHS}$ & $77.2 \%$ & $\begin{array}{l}\text { Widowed or other: } \\
\text { cOR=2.70 }(95 \% \mathrm{CI}=2.17-3.35)\end{array}$ \\
\hline Al-Kuwaiti 2016 & UAE & 151 & $43.7 \%$ & $\begin{array}{l}65.6 \\
(\geq 55)\end{array}$ & $\mathrm{mCHS}$ & $84.1 \%$ & $\begin{array}{l}\text { Divorce, widowed, and unmarried: } \\
\text { cOR=2.89 }(95 \% \text { CI }=1.12-7.45)\end{array}$ \\
\hline Yamanashi 2016 & Japan & 1811 & $63.7 \%$ & $\begin{array}{r}72.2 \\
(>60)\end{array}$ & $\mathrm{mCHS}$ & $68.7 \%$ & $\begin{array}{l}\text { Divorce, widowed, and unmarried: } \\
\text { cOR=2.24 (95\%CI } 1.23-4.08)\end{array}$ \\
\hline
\end{tabular}




\begin{tabular}{|l|c|c|c|c|c|c|l|}
\hline \multicolumn{1}{|c|}{ Author/Year/Study } & Location & $\begin{array}{c}\text { Sample } \\
\text { size }\end{array}$ & $\begin{array}{c}\text { Female } \\
(\%)\end{array}$ & $\begin{array}{c}\text { Age } \\
(\text { range })\end{array}$ & $\begin{array}{l}\text { Frailty } \\
\text { criteria }\end{array}$ & Married & Associations between marital status and frailty risk \\
\hline Op het Veld 2015 & Ireland & 1718 & $52.4 \%$ & $\begin{array}{c}74.0 \\
(\geq 65)\end{array}$ & mCHS & $69.6 \%$ & $\begin{array}{l}\text { Not married: } \\
\text { cOR=2.00 (95\%CI=1.24-3.22) }\end{array}$ \\
\hline $\begin{array}{l}\text { Peklar 2015 } \\
\text { TILDA }\end{array}$ & Cuba & 2339 & $64.7 \%$ & $\begin{array}{c}- \\
(\geq 65)\end{array}$ & mCHS & $44.6 \%$ & $\begin{array}{l}\text { Divorce, widowed, separated, and single: } \\
\text { cOR=1.45 (95\%CI=1.18-1.78) }\end{array}$ \\
\hline $\begin{array}{l}\text { Llibre Jde 2014 } \\
\text { The 10/66 Study }\end{array}$ & Mexico & 1933 & $58.0 \%$ & $\begin{array}{c}71.1 \\
(\geq 60)\end{array}$ & mCHS & $66.4 \%$ & $\begin{array}{l}\text { Not married: } \\
\text { cOR=1.40 (95\%CI=0.87-2.25) }\end{array}$ \\
\hline $\begin{array}{l}\text { Sánchez-García 2014 } \\
\text { SADEM }\end{array}$ & Spain & 523 & $60.3 \%$ & $\begin{array}{c}81.3 \\
(\geq 75)\end{array}$ & mCHS & $50.7 \%$ & $\begin{array}{l}\text { Widowed, separated, and single: } \\
\text { cOR=2.91 (95\%CI=1.53-5.53) }\end{array}$ \\
\hline $\begin{array}{l}\text { Jürschik 2012 } \\
\text { FRALLE }\end{array}$ & Ireland & 544 & $70.7 \%$ & $\begin{array}{c}73 \\
(\geq 60)\end{array}$ & mCHS & $50.6 \%$ & $\begin{array}{l}\text { Divorce, widowed, separated, and never married: } \\
\text { cOR=2.09 (95\%CI=0.77-5.66) }\end{array}$ \\
\hline Ní Mhaoláin 2012 & Taiwan & 929 & $47.6 \%$ & $\begin{array}{c}- \\
(\geq 65)\end{array}$ & mCHS & $71.0 \%$ & $\begin{array}{l}\text { Not married: } \\
\text { cOR=1.98 (95\%CI=1.27-3.09) }\end{array}$ \\
\hline Lin 2011 & USA & 2049 & $58.6 \%$ & $\begin{array}{c}74.4 \\
(67-108)\end{array}$ & mCHS & $54.2 \%$ & $\begin{array}{l}\text { Not married: } \\
\text { cOR=1.50 (95\%CI=1.08-2.08) }\end{array}$ \\
\hline $\begin{array}{l}\text { Masel 2011 } \\
\text { HEPESE }\end{array}$ & Spain & 814 & $51.4 \%$ & $\begin{array}{c}76 \\
(\geq 65)\end{array}$ & mCHS & $64.3 \%$ & $\begin{array}{l}\text { Not married: } \\
\text { uOR=2.39 (95\%CI=1.59-3.61) }\end{array}$ \\
\hline $\begin{array}{l}\text { Alcalá 2010 } \\
\text { Cohort of Peñagrande }\end{array}$ & Canada & 740 & $67.8 \%$ & $\begin{array}{c}79.6 \\
(75-96)\end{array}$ & mCHS & $30.1 \%$ & $\begin{array}{l}\text { Widowed and unmarried: } \\
\text { cOR=1.60 (95\%CI=0.82-3.09) }\end{array}$ \\
\hline $\begin{array}{l}\text { Wong 2010 } \\
\text { MUNS }\end{array}$ & USA & 5993 & $0 \%$ & $\begin{array}{c}73.7 \\
(\geq 65)\end{array}$ & mCHS & $82.3 \%$ & $\begin{array}{l}\text { Not married: } \\
\text { cOR=1.66 (95\%CI=1.23-2.23) }\end{array}$ \\
\hline $\begin{array}{l}\text { Cawthon 2007 } \\
\text { MrOS }\end{array}$ & & & & & \\
\hline
\end{tabular}

aOR: Adjusted odds ratio

CHARLS: China Health and Retirement longitudinal Study

cOR: Calculated odds ratio

COSFOMA: Cohort of Obesity, Sarcopenia and Frailty of Older Mexican Adults

CSHA CFS: Canadian Study of Health and Aging Clinical Frailty Scale

DYNOPTA: Dynamic Analysis to Optimise Ageing Project

EFS: Edmonton Frail Scale

ELSA: English Longitudinal Study of Ageing

FI: Frailty Index

FRALLE: Assessing frailty in elderly people in Lleida

HELIAD: Hellenic Longitudinal Investigation of Aging and Diet

HEPESE: Hispanic Established Populations for Epidemiologic Studies of the Elderly 
HRS: Health and Retirement Study

mCHS: Modified Cardiovascular Health Study criteria

MrOS: Osteoporotic Fractures in Men Study

MUNS: Montreal Unmet Needs Study

NWAHS: North West Adelaide Health Study

Pro.V.A.: Progetto Veneto Anziani

SADEM: Study on Aging and Dementia in Mexico

SIPAF: Système d'Information sur la Perte d'Autonomie Fonctionnelle de la personne âgée

SLAS: Singapore Longitudinal Ageing Study

SOF: Study of Osteoporotic Fractures

TFI: Tilburg frailty indicator

TILDA: The Irish Longitudinal Study of Ageing 
Table 2. Meta-analysis of cross-sectional associations between marital status and frailty and gender-stratified, marital status-stratified, and subgroup analyses (married participants as reference group)

\begin{tabular}{|c|c|c|c|c|c|c|}
\hline & $\begin{array}{l}\text { Number of } \\
\text { studies }\end{array}$ & $\begin{array}{l}\text { Pooled odds ratio } \\
\qquad(95 \% \mathrm{CI})\end{array}$ & $\mathrm{p}$ & $\begin{array}{c}\mathrm{P} \text { for } \\
\text { heterogeneity }\end{array}$ & $\mathrm{I}^{2}$ & $\begin{array}{c}\mathrm{p} \text { for } \\
\text { subgroup } \\
\text { differences }\end{array}$ \\
\hline Total & 35 & $1.88(1.70-2.07)$ & $<0.001$ & $<0.001$ & $69 \%$ & - \\
\hline \multicolumn{7}{|l|}{ Gender-stratified } \\
\hline Female only & 15 & $1.74(1.42-2.13)$ & $<0.001$ & $<0.001$ & $81 \%$ & 0.62 \\
\hline Male only & 16 & $1.86(1.55-2.24)$ & $<0.001$ & 0.01 & $49 \%$ & \\
\hline \multicolumn{7}{|l|}{ Subgroup } \\
\hline \multicolumn{7}{|l|}{ Location } \\
\hline Europe & 10 & $2.33(2.11-2.57)$ & $<0.001$ & 0.64 & $0 \%$ & ref \\
\hline Asia & 9 & $2.25(2.01-2.53)$ & $<0.001$ & 0.64 & $0 \%$ & 0.67 \\
\hline USA/Canada & 4 & $1.81(1.43-2.29)$ & $<0.001$ & 0.06 & $59 \%$ & 0.05 \\
\hline Brazil & 6 & $1.39(1.22-1.59)$ & $<0.001$ & 0.62 & $0 \%$ & $<0.001$ \\
\hline Others & 6 & $1.49(1.33-1.68)$ & $<0.001$ & 0.30 & $17 \%$ & $<0.001$ \\
\hline \multicolumn{7}{|l|}{ Sample size } \\
\hline $\mathrm{n}<2000$ & 23 & $1.86(1.63-2.12)$ & $<0.001$ & 0.02 & $42 \%$ & ref \\
\hline$n>=2000$ & 12 & $1.90(1.63-2.20)$ & $<0.001$ & $<0.001$ & $85 \%$ & 0.84 \\
\hline \multicolumn{7}{|l|}{ Mean age* } \\
\hline$<75$ & 21 & $1.93(1.73-2.16)$ & $<0.001$ & $<0.01$ & $54 \%$ & ref \\
\hline$>=75$ & 8 & $1.88(1.44-2.45)$ & $<0.001$ & $<0.001$ & $75 \%$ & 0.85 \\
\hline \multicolumn{7}{|l|}{$\begin{array}{l}\text { Marital status-stratified } \\
\text { (vs. married) }\end{array}$} \\
\hline Widowed & 12 & $2.11(1.86-2.39)$ & $<0.001$ & 0.11 & $35 \%$ & ref \\
\hline Divorced/separated & 10 & $1.73(1.42-2.11)$ & $<0.001$ & 0.19 & $29 \%$ & 0.10 \\
\hline Never married & 7 & $1.37(1.06-1.79)$ & 0.02 & 0.74 & $0 \%$ & $<0.01$ \\
\hline
\end{tabular}

CI: Confidence interval

* 6 studies did no provide mean age. 
Figure 1. Flow chart of systematic literature review.
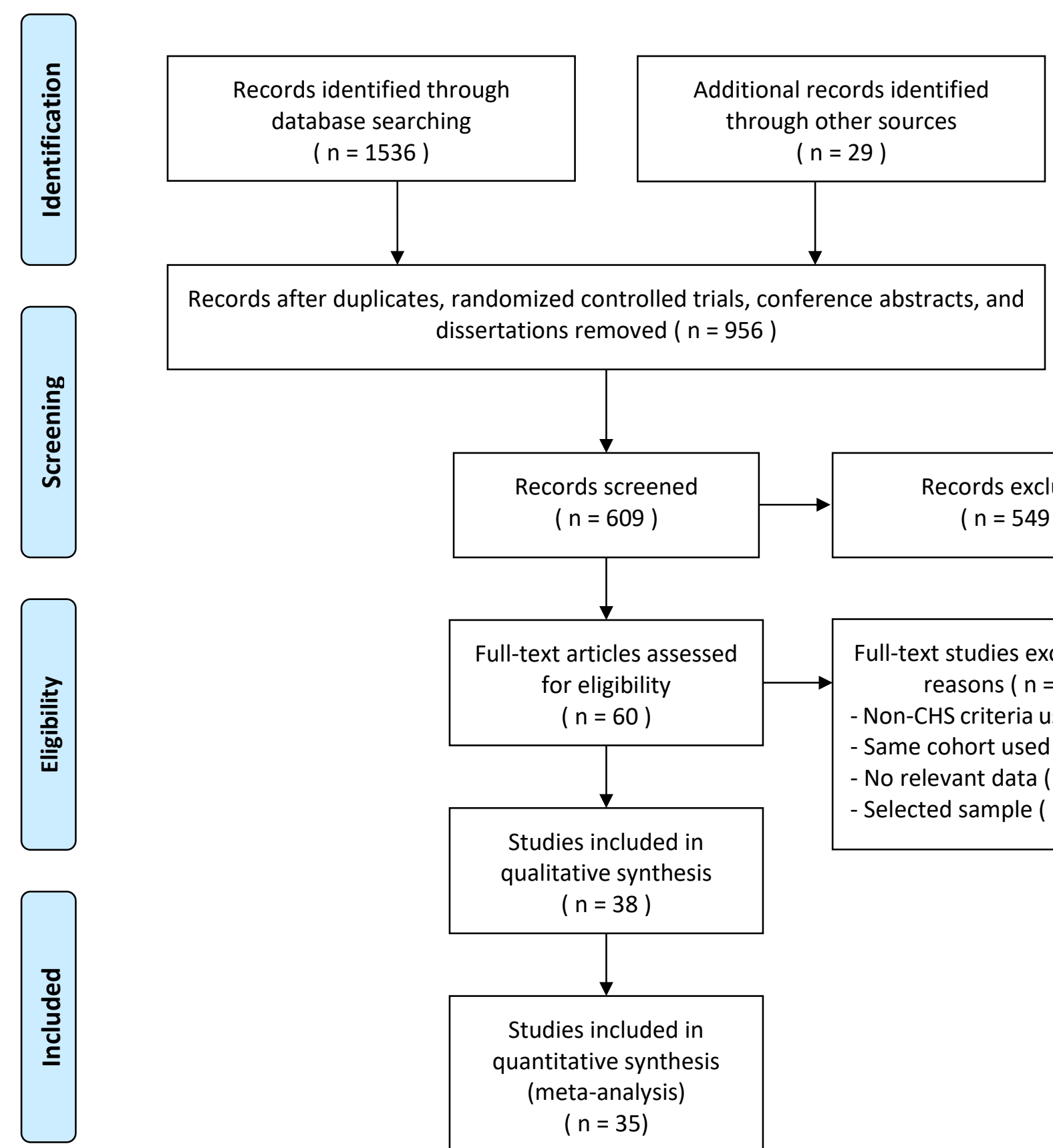
Records after duplicates, randomized controlled trials, conference abstracts, and dissertations removed $(n=956)$

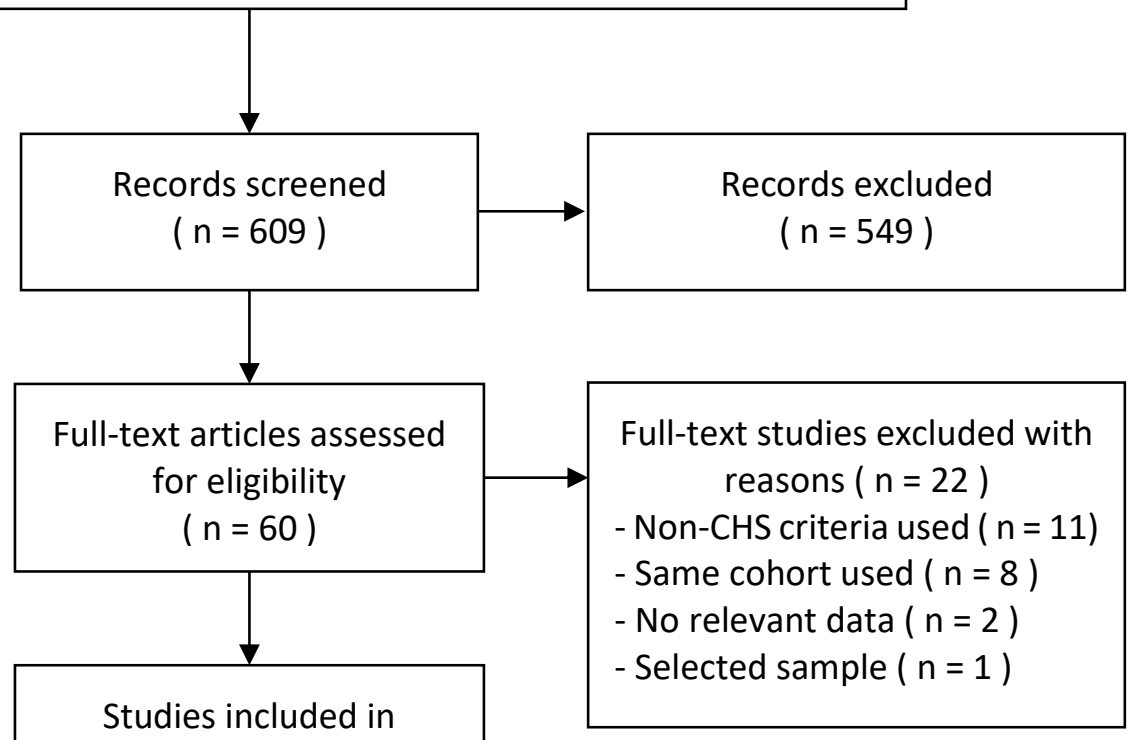

qualitative synthesis

$$
(n=38)
$$

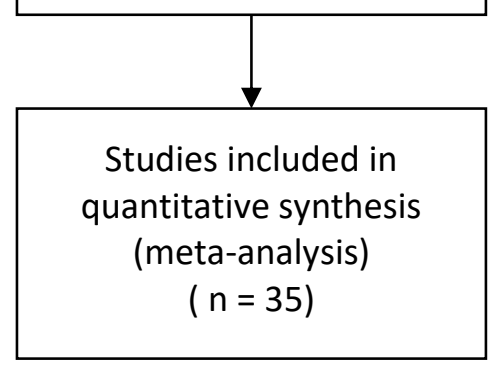


Figure 2. Forest plot of association between marital status and frailty.

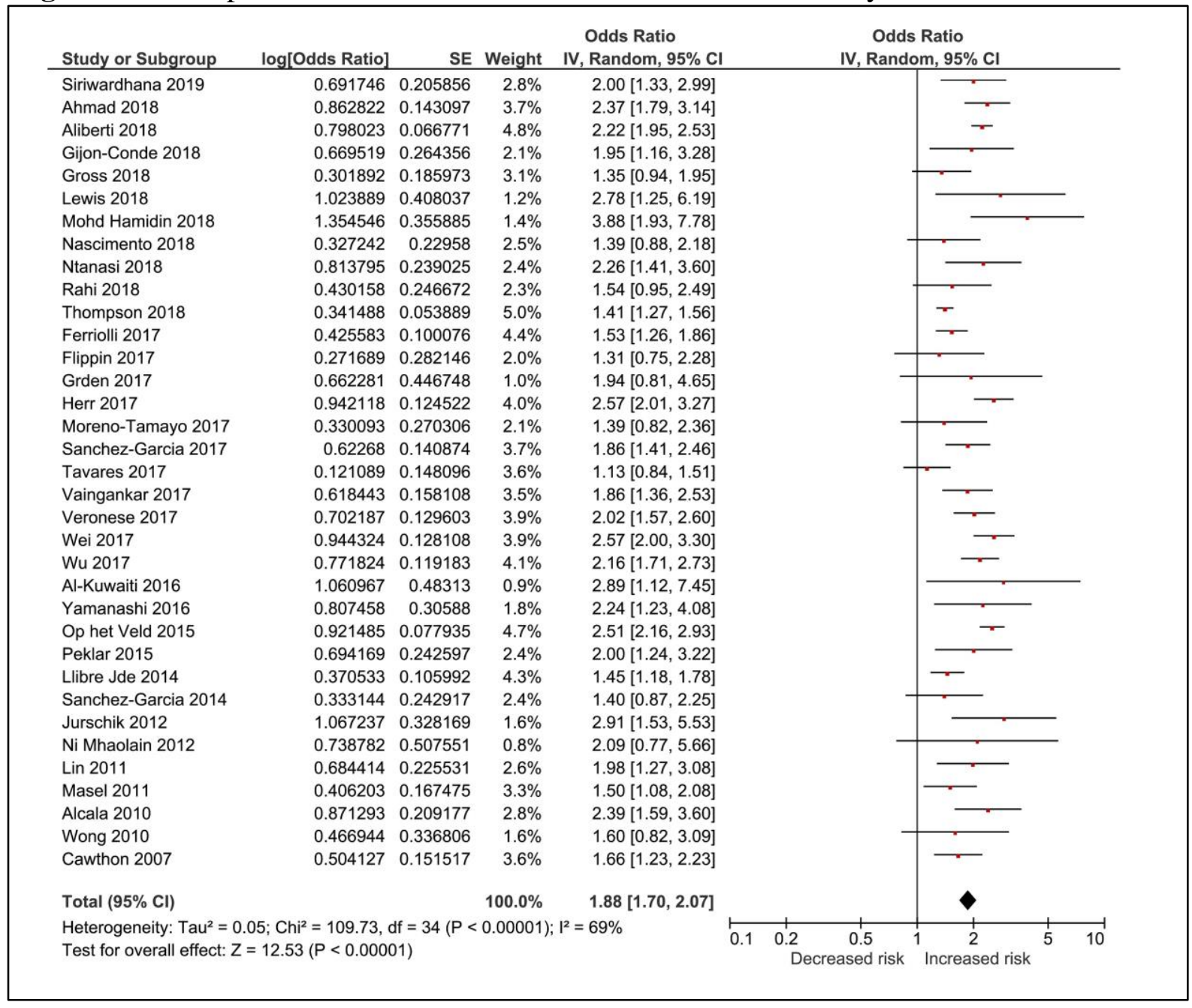

